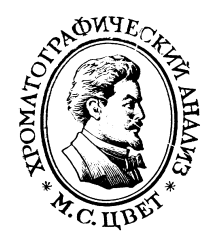

УДК 541.18

\title{
О полифункциональности высокоосновных анионитов
}

\author{
Славинская Г.В. ${ }^{1}$, Куренкова О.В. ${ }^{2}$ \\ ${ }^{l}$ ФГБОУ ВО «Воронежский государственный политехнический университет», Воронеж \\ ${ }^{2}$ Кадетский корпус (инженерная школа) Военного учебно-научного иентра Военно-воздушных сил \\ «Военно-воздушная академия имени профессора Н.Г. Жуковского и Ю.А. Гагарина», Воронеж
}

Поступила в редакцию 29.08.2017 г.

DOI: https://doi.org/10.17308/sorpchrom.2019.19/655

Методом потенциометрического титрования в высокоосновном анионите AB-17-8 установлено наличие трех типов функциональных групп. Определены константы их ионизации: $\mathrm{pK}_{\mathrm{bl}}=1.72 \div 1.78$; $\mathrm{pK}_{\mathrm{b} 2}=4.32 \div 4.38 ; \mathrm{pK}_{\mathrm{b} 3}=7.72 \div 7.82$. В ионный обмен с кремниевыми кислотами вступают две функциональные группы с меньшими величинами $\mathrm{pK}_{\mathrm{b}}$. Доля слабоосновных групп (c $\left.\mathrm{pK}_{\mathrm{b} 3}=7.72 \div 7.82\right)$ в разных партиях анионита достигает $12-34 \%$ от полной обменной емкости. Полифункциональность анионита AB-17-8 нужно учитывать при обсуждении различных закономерностей ионообменных процессов, а также при прогнозировании сорбции анионов слабых органических и минеральных кислот.

Ключевые слова: высокоосновный анионит, потенциометрическое титрование, функциональные группы, константы диссоциации, обменная емкость

\section{On the multifunctional character of strong basic anion-exchange resin}

\author{
Slavinskaya G.V ${ }^{1}$, Kurenkova O.V. ${ }^{2}$ \\ ${ }^{I}$ FSAEI HE Voronezh State Technical University, Voronezh \\ ${ }^{2}$ Cadet School (Engineering School) of the Air Force «Military Air Academy Named after \\ N. Ye. Zhukovsky and Yu. A. Gagarin»,Voronezh
}

The method of potentiometric titration for the strong basic anion-exchange resin AB-17-8, synthesized on a styrene-divinylbenzene matrix, revealed the presence of three kinds of functional groups. Their presence is confirmed by non-aqueous titration of anion-exchange resin samples with a solution of perchloric acid in acetone in the «isopropyl alcohol-ethylene glycol» medium in a 1:1 ratio by volume. The ionization constants of ionogenic groups that can characterize strongly dissociated benzyltrimethylammonium groups $\left(\mathrm{pK}_{\mathrm{b} 1}=1.72 \div 1.78\right)$ are determined; tertiary, secondary and primary amino groups located in the aliphatic chain of the matrix have $\mathrm{pK}_{\mathrm{b} 2}=4.32 \div 4.38$; tertiary, primary and secondary amino groups attached directly to the aromatic ring have $\mathrm{pK}_{\mathrm{b} 3}=7.72 \div 7.82$. It turned out that only the first two groups with low $\mathrm{pK}_{\mathrm{b}}$ values participate in the ion exchange with silicic acid. The content of weakly dissociating ionogenic groups with $\mathrm{pK}_{\mathrm{b} 3}=7.72 \div 7.82$ in different batches of anion-exchange resin can be as much as $12 \div 34 \%$ according to our data. This fact (polyfunctionality of the anion-exchange resin) must be taken into account when discussing the various regularities of ion-exchange processes, as well as in predicting the sorption of anions of weak organic and mineral acids.

Keywords: high-basic anion-exchange resin, potentiometric titration, functional groups, dissociation constants, exchange capacity 


\section{Введение}

Высокоосновные анионообменники (далее аниониты) востребованы в технологиях, предполагающих сорбцию слабых электролитов, например угольной, кремниевой, гуминовых, амино- и фульвокислот, а также анионов синтетических поверхностно-активных соединений [1-4] и др.

Аниониты этого типа используют в системах ионитной подготовки воды для удаления анионов угольной и кремниевых кислот [1]. Известно, что ионный обмен возможен только с участием диссоциированных функциональных групп ионообменника и ионизированных компонентов в растворе [5]. Однако, как оказалось, не все функциональные группы высокоосновных анионитов могут диссоциировать в нейтральной среде, которая имеет место, например при обескремнивании и декарбонизации воды в процессе ее глубокого обессоливания.

В литературе с момента синтеза еще долгое время высокоосновные аниониты считались монофункциональными [6-10]. Присутствие ионогенных групп в высокоосновном анионите АВ-17-8, неактивных при удалении слабых кислот (угольной и кремниевой), обнаружили в [1]. Кроме того, было замечено [11], что солевые формы трудно отмыть до отсутствия противоионов в промывных водах, что обычно характерно для низкоосновных анионитов. Авторы [11] предположили среди вероятных причин этого явления наличие в ионите слабодиссоциированных функциональных групп, то есть аминогрупп, которые при контакте с водой гидролизуются с отдачей противоиона во внешний раствор.

При технологических расчетах, когда планируется длительность рабочего периода, например, обескремнивающего фильтра, долю слабоионизированных функциональных групп в анионите нужно учитывать обязательно, так как часть обменной емкости фильтра не будет вовлечена в сорбционный процесс. Какая? Для ответа на этот вопрос нужно оценить константы ионизации низкоосновных функциональных групп анионита и определить их количество.

\section{Теоретическая часть}

Наиболее полную характеристику ионогенных групп в ионообменнике дает метод потенциометрического титрования $[5,11]$.

Ионизацию анионита в гидроксидной форме описывает уравнение:

$$
\mathrm{R}-\mathrm{OH} \leftrightarrow \mathrm{R}^{+}+\mathrm{OH}^{-}
$$

В равновесном состоянии константа равновесия, то есть константа диссоциации анионита $\left(\mathrm{K}_{\mathrm{b}}\right)$, запишется как:

$$
K_{b}=\frac{\left.\overline{\left[R^{+}\right.}\right]\left[\overline{O H^{-}}\right]}{[\overline{R O H}]}
$$

В начальный момент времени, когда в анионите содержатся только $\mathrm{OH}^{-}$группы, их доля равна 1 , то есть значение $[\mathrm{ROH}]=1$ [12]. По мере дозирования титранта (например $\mathrm{HCl}$ ) даже самые слабые ионогенные группы анионита переводятся в солевую форму и начинают диссоциировать, при этом доля недиссоциированных групп [ROH] снижается, а доля диссоциированных групп $\left[\mathrm{R}^{+}\right]$увеличивается. Количество функциональных групп, оставшихся без $\mathrm{OH}^{-}$- иона, равно степени ионизации, то есть $\left[\mathrm{R}^{+}\right]=\alpha$. Тогда оставшаяся неионизированная часть $[\mathrm{ROH}]$ в ионите равна $(1-\alpha)$. 
Логарифмирование уравнения (1) и изменение знаков на противоположные (по аналогии вывода уравнения для диссоциации катионита [12]) приводит к выражению:

$$
-\lg \mathrm{K}_{\mathrm{b}}=-\lg \left[\mathrm{R}^{+}\right]-\lg \left[\mathrm{OH}^{-}\right]+\lg [\mathrm{ROH}] .
$$

После обозначения: $-\lg \mathrm{K}_{\mathrm{b}}=\mathrm{pK}$; $-\lg \left[\mathrm{OH}^{-}\right]=\mathrm{pOH}$,

$$
\mathrm{pK}_{\mathrm{b}}=\mathrm{pOH}+\lg \frac{[R O H]}{\left[R^{+}\right]}=p O H+\lg \frac{1-\alpha}{\alpha} .
$$

Тогда для анионита:

$$
\mathrm{pOH}=\mathrm{pK}_{\mathrm{b}}-\lg \frac{1-\alpha}{\alpha} .
$$

Это уравнение прямой в координатах $\mathrm{pOH}=\mathrm{f}(\lg [(1-\alpha) / \alpha])$ с углом наклона к оси абсцисс $45^{\circ}$, то есть с тангенсом, равным единице. Однако это условие не всегда выполняется. Отмечено, что при графическом представлении кривых титрования, значения тангенса угла наклона прямой могут быть как больше, так и меньше единицы. Чтобы учитывать это обстоятельство, был введен параметр «n», и уравнение приняло вид [13, 14]:

$$
\mathrm{pOH}=\mathrm{pK}_{\mathrm{b}}-\mathrm{nlg} \frac{1-\alpha}{\alpha} .
$$

Это модифицированное уравнение Гендерсона-Гассельбаха: используется для расчета констант ионизации ионогенных групп ионообменников. При его выводе приняты некоторые допущения, в том числе значение $\mathrm{pOH}$ внешнего раствора считают равным рОН среды в фазе ионита $(p O H \approx p O \bar{H})$, но это предположение не имеет экспериментальных доказательств, так как отсутствуют надежные методы таких измерений. Найденную при данном допущении константу диссоциации принято считать «кажущейся» (то есть «условной») [5, 13].

В уравнении (4) $n$ - параметр, по поводу которого нет единого мнения. Например, в $[6,15]$ указано, что это фактор, учитывающий электростатическое взаимодействие соседних ионогенных групп ионита, а именно влияние соседних функциональных групп на ионизацию данной группы [16]. По мнению авторов $[13,17]$, величина $\mathrm{n}$ характеризует конфигурационную энтропию матрицы. В работе [18] предполагается зависимость параметра $\mathrm{n}$ от концентрации функциональных групп. Причем, по мнению [18], величина $\mathrm{n}$ тем больше, чем больше концентрация последних в ионите. Другие авторы [12] представляют $\mathrm{n}$ как некоторую постоянную, характеризующую степень сшитости полимера. В [19] этот параметр без объяснения физического смысла называют просто постоянной величиной.

\section{Эксперимент}

Объекты исследования. К сильноосновным относятся аниониты типа AB-17, полученные сополимеризацией стирола и дивинилбензола с последующим хлорметилированием и аминированием сополимера триметиламином [20, 21]. Функциональными являются сильно диссоциирующие бензилтриметиламмониевые группы. Предполагаемая формула составного повторяющегося звена показана на рис.1.

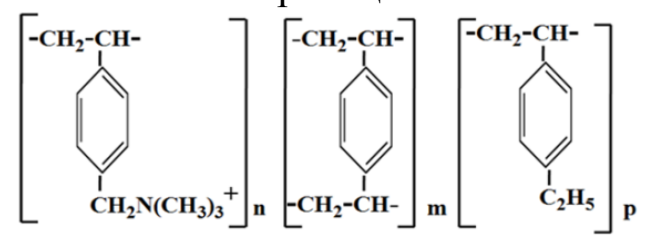

Рис. 1. Строение составного повторяющегося звена анионита АВ-17-8 [21]

Славинская и др / Сорбционные и хроматографические процессы. 2019. Т. 19. № 1 
В эксперименте исследованы аниониты АВ-17-8 промышленного производства, не бывшие в эксплуатации, а также после одного года работы в промышленной ионообменной установке, обессоливающей речную воду; аниониты, хранившиеся на предприятии в сухом состоянии один, три и пять лет; анионит АВ-17-8чС исходный и работавший, а также до и после кондиционирования.

Набухший анионит переносили в фильтр Шотта с пористой стеклянной перегородкой и регенерировали 1 моль/дм ${ }^{3}$ раствором $\mathrm{NaOH}$ для перевода анионита из углекислотной формы в гидроксидную. Эта операция выполнялась потому, что высокоосновный анионит при хранении, даже находясь под слоем воды, поглощает углекислоту, в результате чего $\mathrm{R}-\mathrm{OH}$ превращается в $\mathrm{R}-\mathrm{HCO}_{3}$. Для отмывки анионита от щелочи использовали обессоленную обескремненную воду, из которой удалена углекислота кипячением в течение 10 мин. Воду хранили в колбе с плотной пробкой, в которой имелись сифон для отбора воды и трубка с натронной известью для защиты содержимого от атмосферного $\mathrm{CO}_{2}$.

Свежерегенерированный и отмытый от щелочи анионит переносили в стаканчик с пористым дном и отделяли воду на центрифуге ЦЛН-2. Затем брали точные навески анионита: одну - для титрования, две - для определения влагосодержания с целью нахождения массы абсолютно-сухого анионита в титруемой пробе. Навеску, предназначенную для титрования, измельчали в агатовой ступке в течение 1-2 минут. Раствор 1.0 моль/дм ${ }^{3} \mathrm{KCl}$ нагревали до $50^{\circ} \mathrm{C}$. Этим раствором быстро смывали навеску в реакционную ячейку.

Титрант - раствор 0.1 моль/дм ${ }^{3} \mathrm{HCl}$ в 1.0 моль/дм ${ }^{3}$ растворе $\mathrm{KCl}$. Подогрев и перемешивание системы осуществляли на магнитной мешалке. В ячейку для защиты содержимого от $\mathrm{CO}_{2}$ воздуха подавали аргон. Титрант дозировали из микробюретки по 0.1 мл раствора (0.01 ммоль кислоты) и выдерживали до достижения состояния равновесия, то есть до стабилизации значений $\mathrm{pH}$. Кривые потенциометрического титрования анионита AB-17-8 в таких условиях даны на рис. 2.

Судя по форме кривых титрования, в анионите имеются ионогенные группы трех типов. Все другие образцы анионитов, перечисленные выше, характеризуются аналогичной формой кривых потенциометрического титрования.

После описанной серии опытов были проведены эксперименты при обычных условиях, без подогрева и измельчения пробы. Имелись опасения, что при использовании метода одной навески не будет устанавливаться равновесие в системе. Однако, как следует из опыта авторов [6], при использовании мелкозернистых фракций анионита это не является большой помехой при технических исследованиях ионитов, так как система асимптотически приближается к равновесию и достигает такого состояния, при котором ошибка от недостигнутого полного равновесия становится пренебрежимо малой [6].

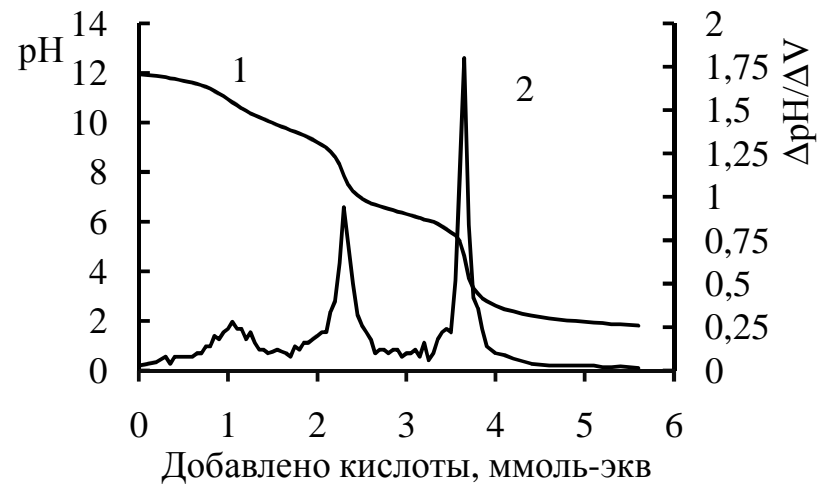

Рис. 2. Интегральная (1) и дифференциальная (2) кривые титрования анионита AB-17-8 
Для доказательства факта достижения равновесия определена статическая полная обменная емкость (COE) анионита $\mathrm{AB}-17-8$ по растворам $\mathrm{HCl}$ и $\mathrm{NaCl}$ по [22] и сопоставлена с результатами потенциометрического титрования (табл. 1).

Таблица 1. Обменная емкость образцов анионита АВ-17-8 ( \pm 0.02 ммоль-экв/г), определенная разными способами

\begin{tabular}{|c|c|c|c|c|c|c|}
\hline \multirow{2}{*}{ Образец } & \multicolumn{3}{|c|}{ по 0.1 моль/дм ${ }^{3} \mathrm{HCl}$} & \multicolumn{3}{c|}{ по 0.1 моль/дм ${ }^{3} \mathrm{NaCl}$} \\
\cline { 2 - 7 } & Титров. & СОЕ & \% расх. & Титров. & СОЕ & \% расх. \\
\hline АВ-17-8. № 1 & 3.59 & 3.51 & +2.6 & 2.86 & 2.86 & -0.1 \\
\hline AB-17-8. № 2 & 3.50 & 3.42 & +1.9 & 2.74 & 2.65 & +3.4 \\
\hline AB-17-8. № 3 & 3.13 & 3.25 & -3.8 & 2.50 & 2.58 & -3.3 \\
\hline AB-17-8. № 4 & 3.08 & 2.96 & +3.8 & 2.22 & 2.20 & +0.8 \\
\hline AB-17-8чC & 4.30 & 4.43 & -3.0 & 3.76 & 3.88 & -3.1 \\
\hline
\end{tabular}

Как следует из данных табл. 1, расхождение в величинах ПОЕ, определенных обоими методами, незначительное - не более трех-четырех процентов в обе стороны. Это значит, что за время проведения титрования (обычно около трех часов) равновесие в системе «титрант-раствор» устанавливается. На этом основании все дальнейшие эксперименты (с 25-ю образцами анионита) проведены методом одной навески на мелких фракциях анионитов при комнатной температуре. По мнению авторов [12], это допустимо при исследовании сильнодиссоциирующих ионообменников.

Были сомнения относительно первого перегиба кривой интегральной, хотя на дифференциальной наличие первого пика очевидно. Такие ситуации отмечены при титровании смесей сильного и слабого электролитов [23]. Тем не менее, для уточнения количества типов ионогенных групп, проводилось титрование анионита в неводных средах [24], результаты которого подтвердили присутствие трех активных групп в анионите АВ-17-8 (рис. 3).

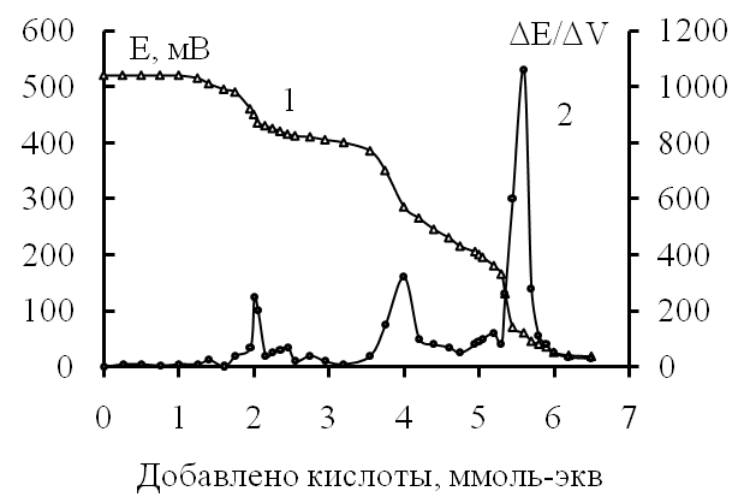

Рис. 3. Интегральная (1) и дифференциальная (2) кривые титрования анионита AB-17-8: E - потенциал, мВ. V- объем прибавленной кислоты, см${ }^{3}$

Влажные навески помещали в смесь растворов этиленгликоля и изопропилового спирта, взятых в соотношении по объему $1: 1$. Титрант - раствор хлорной кислоты в ацетоне или диоксане. Титр $\mathrm{HClO}_{4}$ устанавливали по бифталату калия.

\section{Обсуждение результатов}

Для определения констант ионизации ионогенных групп анионита AB-17-8 использовали зависимость $\lg [(1-\alpha) / \alpha]$ - $\mathrm{pOH}$. Этот способ позволяет находить объективные значения $\mathrm{pK}$. Пример его определения показан на рис. 4. 
Прямая 1 описывается уравнением: $\mathrm{y}_{1}=-1.105 \mathrm{x}+7.867$; прямая 2 - уравнением $\mathrm{y}_{2}=-1.179 \mathrm{x}+4.336$; прямая 3 - уравнением: $\mathrm{y}_{3}=-0.795 \mathrm{x}+1.743$. Эти линии соответствуют уравнению (3): $\mathrm{pOH}=\mathrm{pK}_{\mathrm{b}}-\mathrm{nlg}[(1-\alpha) / \alpha]$.

Здесь свободный член - отсекаемый отрезок оси ординат, есть величинарК функциональных групп анионита; множитель перед числом х - параметр n, то есть тангенс угла наклона прямой к оси абсцисс; $\mathrm{x}-$ это $\lg [(1-\alpha) / \alpha]$.

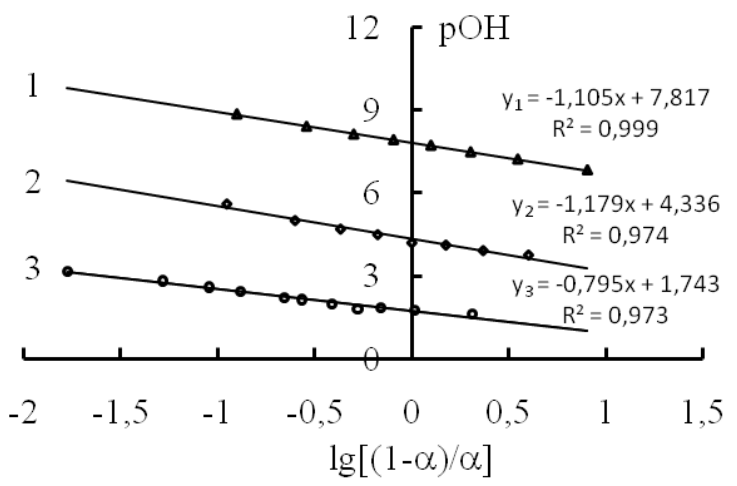

Рис. 4. Зависимость рОН равновесного раствора от величины $\lg [(1-\alpha) / \alpha]$

Тогда для кривой титрования до первого перегиба $\mathrm{n}_{1}=0.795$ и $\mathrm{pK}_{\mathrm{b} 1}=1.743$; для второго участка $\mathrm{n}_{2}=1.179$ и $\mathrm{pK}_{\mathrm{b} 2}=4.336$; для третьего: $\mathrm{n}_{3}=1.105$ и $\mathrm{pK}_{\mathrm{b} 3}=7.867$ при высокой степени аппроксимации от 0.973 до 0.999. Как видно, параметр n принимает значения как меньшие, так и большие единицы. С его учетом рассчитаны средние значения (ср.) констант $\mathrm{pK}_{\mathrm{b}}$ по уравнению (4) (табл. 2).

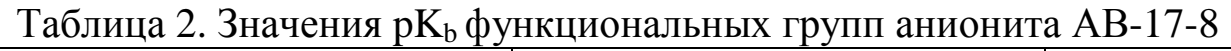

\begin{tabular}{|c|c|c|c|c|c|}
\hline \multicolumn{2}{|c|}{$\begin{array}{c}\mathrm{y}=-1.105 \mathrm{x}+7.867 \\
\left(\mathrm{R}^{2}=0.999\right)\end{array}$} & \multicolumn{2}{c|}{$\mathrm{y}=-1.179 \mathrm{x}+4.336$} & \multicolumn{2}{c|}{$\begin{array}{c}\mathrm{y}=-0.795 \mathrm{x}+1.743 \\
\left(\mathrm{R}^{2}=0.974\right)\end{array}$} \\
\hline $\mathrm{pOH}$ & $\mathrm{pK}_{\mathrm{b} 1}$ & $\mathrm{pOH}$ & $\mathrm{pK}_{\mathrm{b} 2}$ & $\mathrm{pOH}$ & $\mathrm{pK}_{\mathrm{b} 3}$ \\
\hline 8.85 & 7.85 & 5.61 & 4.49 & 3.17 & 1.76 \\
\hline 8.40 & 7.80 & 5.01 & 4.30 & 3.05 & 1.78 \\
\hline 8.12 & 7.80 & 4.72 & 4.27 & 2.24 & 1.72 \\
\hline 7.72 & 7.83 & 4.21 & 4.20 & 1.79 & 1.87 \\
\hline 7.48 & 7.82 & 4.12 & 4.33 & 1.77 & 1.78 \\
\hline 6.83 & 7.83 & 3.92 & 4.35 & 1.64 & 1.89 \\
\hline \multicolumn{2}{c|c}{$\mathrm{cp} \cdot \mathrm{pK}_{\mathrm{b} 1}=7.82 ; \mathrm{K}_{\mathrm{b} 1}=1.51 \cdot 10^{-8}$} & cp. $\mathrm{pK}_{\mathrm{b} 2}=4.35 ; \mathrm{K}_{\mathrm{b} 2}=4.46 \cdot 10^{-5}$ & \multicolumn{2}{c|}{$\mathrm{cp} \cdot \mathrm{pK}_{\mathrm{b} 3}=1.78 ; \mathrm{K}_{\mathrm{b} 3}=1.66 \cdot 10^{-2}$} \\
\hline
\end{tabular}

Таким способом были обработаны результаты титрования всех партий анионита: определены $\mathrm{pK}_{\mathrm{b}}$, полная обменная емкость (ПОЕ) и емкость отдельно по трем типам ионогенных групп $\left(\mathrm{E}_{1}, \mathrm{E}_{2}, \mathrm{E}_{3}\right)$. Данные сведены в табл. 3.

Найденные значения $\mathrm{pK}_{\mathrm{b}}\left(1.78 ; 4.35\right.$ и 7.82) вписываются в интервалы $\mathrm{pK}_{\mathrm{b}}$, предположительно характеризующие ионогенные группы разной силы [6]: с $\mathrm{pK}_{\mathrm{b}}=1 \div 2$ - сильно диссоциирующие четвертичные алкиламмониевые; с $\mathrm{pK}_{\mathrm{b}}=3 \div 5$ третичные, вторичные и первичные аминогруппы, расположенные в алифатической цепочке матрицы; с $\mathrm{pK}_{\mathrm{b}}=6 \div 9$ - третичные и вторичные аминогруппы, присоединенные непосредственно к ароматическому кольцу [6].

Представлялось обязательным выяснение типов ионогенных групп анионита AB-17-8, которые участвуют в сорбции кремниевых кислот (табл. 4). 
Таблица 3. Обменная емкость и $р K_{\mathrm{b}}$ ионогенных групп проб анионита AB-17-8

\begin{tabular}{|c|c|c|c|c|c|c|c|c|}
\hline \multirow{2}{*}{ Образец } & \multicolumn{7}{|c|}{ Обменная емкость $( \pm 0,02)$ ммоль-экв/Г } & \multicolumn{2}{c|}{$\mathrm{pK}$ ионогенных групп } \\
\cline { 2 - 9 } & $\mathrm{E}_{1}$ & $\mathrm{E}_{2}$ & $\mathrm{E}_{3}$ & ПОЕ & $\mathrm{E}_{1}+\mathrm{E}_{2}$ & $\mathrm{pK}_{1}$ & $\mathrm{pK}_{2}$ & $\mathrm{pK}_{3}$ \\
\hline \multicolumn{8}{|c|}{ Свежие образцы } \\
\hline Свежий & 2.32 & 0.54 & 0.64 & 3.50 & 2.86 & 1.99 & 4.35 & 7.70 \\
\hline То же & 2.38 & 0.54 & 0.64 & 3.56 & 2.92 & 1.97 & 4.25 & 7.85 \\
\hline Партия 1 & 2.66 & 0.71 & 0.76 & 4.13 & 3.37 & 1.77 & 4.18 & 7.71 \\
\hline Партия 2 & 3.32 & 0.56 & 0.65 & 4.53 & 3.88 & 1.88 & 4.20 & 7.85 \\
\hline \multicolumn{8}{|c|}{ Хранившиеся образцы } \\
\hline 1 год & 2.77 & 0.45 & 0.42 & 3.64 & 3.22 & 1.80 & 4.29 & 7.82 \\
\hline 3 года & 1.95 & 0.29 & 0.43 & 2.67 & 2.24 & 2.09 & 4.09 & 7.85 \\
\hline 5 лет & 2.12 & 0.35 & 0.34 & 2.81 & 2.47 & 2.01 & 4.25 & 7.85 \\
\hline \multicolumn{8}{|c|}{ До и после кондиционирования } \\
\hline Исходн. & 2.41 & 0.54 & 0.53 & 3.48 & 2.95 & 2.03 & 4.30 & 7.87 \\
\hline Кондиц. & 2.17 & 0.35 & 0.30 & 2.82 & 2.52 & 2.05 & 4.28 & 7.80 \\
\hline \multicolumn{8}{|c|}{ После эксплуатации в промышленной обессоливающей установке } \\
\hline До обраб. & 1.73 & 0.55 & 0,46 & 2.74 & 2.28 & 1.97 & 4.70 & 7.85 \\
\hline Обработ.* & 2.00 & 0.52 & 0.76 & 3.28 & 2.52 & 1.99 & 4.42 & 7.78 \\
\hline
\end{tabular}

*Анионит трижды обработан раствором $\mathrm{NaOH}$ в $\mathrm{NaCI}$.

Таблица 4. Обменная емкость образцов анионита AB-17-8 ( \pm 0.02 ммоль-экв/г) по сумме ионогенных групп и кремниевой кислоте

\begin{tabular}{|c|c|c|c|c|c|c|}
\hline \multirow{2}{*}{ Образец } & \multicolumn{3}{|c|}{ Количество ионогенных групп, ммоль-экв/Г } & \multicolumn{2}{c|}{ Емкость, ммоль-экв/Г } \\
\cline { 2 - 7 } & $\mathrm{E}_{1}$ & $\mathrm{E}_{2}$ & ПОЕ & $\mathrm{E}_{1}+\mathrm{E}_{2}$ & по $\mathrm{HSiO}_{3}^{-}$ & по $\mathrm{NaCl}$ \\
\hline $\mathrm{AB}-17-ч C$ & 3.32 & 0.55 & 4.42 & 3.87 & 3.75 & 3.80 \\
\hline $\mathrm{AB}-17-8 ч$ & 3.30 & 0.50 & 4.34 & 3.80 & 3.88 & 3.72 \\
\hline $\mathrm{AB}-17-8$ & 3.24 & 0.49 & 4.22 & 3.73 & 3.73 & 3.79 \\
\hline
\end{tabular}

Судя по данным табл. 4, емкость по $\mathrm{HSiO}_{3}^{-}$- анионам обеспечивают две группы с меньшими значениями $\mathrm{pK}_{\mathrm{b}}$ (как и сорбцию хлорид-ионов из растворов $\mathrm{NaCl})$. Количество низкоосновных групп (с $\left.\mathrm{pK}_{\mathrm{b} 3}=7.72 \div 7.82\right)$ необходимо учитывать при исследовании сорбции анионитом AB-17-8 слабых электролитов $[2-4,6]$ и в технологических расчетах его работы в таких системах $[1,2]$.

Влияние времени хранения анионита на его свойства. Анионит AB-17-8 используют в системах ионитной подготовки воды для удаления кремниевых кислот в монофильтрах, а также для окончательного дообессоливания в фильтрах смешанного действия (ФСД) [6]. Ухудшение его первоначальных свойств делает невозможным получение высокоомной воды, так как кроме кремниевых кислот в воде остается еще угольная кислота. Даже при малых величинах констант ионизации они заметно снижают величину удельного электрического сопротивления воды. Поэтому к обескремнивающему иониту предъявляются особые требования - хорошие кинетические свойства и высокая обменная емкость в отношении анионов слабых кислот.

Судя по приведенным в табл. 3 данным, основное падение емкости происходит в течение первых трех лет. Показательно, что теряются именно сильноосновные группы с $\mathrm{pK}_{\mathrm{b}} \sim 1.8$ и $\mathrm{pK}_{\mathrm{b}} \sim 4.3$. Их количество становится меньше на $24 \%$ за первые три года эксплуатации и на $30 \%$ - за пять лет. Эти изменения в количестве высокоосновных групп не могли не сказаться на динамической обменной емкости по кремниевой кислоте. Она уменьшилась с 1.11 ммоль-экв/см ${ }^{3}$ набухшего образца, работавшего 1 год, до 0.74 и 0.52 через 3 и 5 лет соответственно. Следует отметить, что сумма ионогенных групп первых двух типов изменилась в течение пяти лет незначительно: от 88.8 до 87.7 и $84.0 \%$. 
Влияние кондиционирования на свойства анионита. Особое внимание уделено нами результатам кондиционирования анионитов, которое проводится в любых экспериментах перед изучением взаимодействия ионообменников с другими веществами. Исследован анионит АВ-17-8чС в объеме 4.0 дм³ $^{3}$ Размер зерен $0.5 \div 1.0$ мм. Кондиционирование заключалось в последовательном проведении следующих операций. После замачивания и набухания в насыщенном растворе $\mathrm{NaCl}$, отмывки от соли обессоленной водой, затем для извлечения ионов железа растворами соляной кислоты повышающейся концентрации 1.0, 2.0 и 3.0 моль/дм ${ }^{3}$, отмывки водой от кислоты проведена регенерация анионита 0.5 моль/дм ${ }^{3}$ раствором $\mathrm{NaOH}\left(40\right.$ дм $\left.^{3}\right)$. После отмывки от щелочи пропущено 60 дм $^{3}$ раствора 0.5 моль/дм ${ }^{3}$ НСI для перевода анионита из гидроксидной в хлоридную форму, то есть для его полной отработки по хлорид-иону. Проведено три таких цикла щелочно-кислотной обработки загрузки колонки. После чего осуществлена глубокая регенерация анионита 0.5 моль/дм ${ }^{3}$ раствором $\mathrm{NaOH}$ с расходом 80 дм $^{3}$.

На кривых потенциометрического титрования выявлены три пика. Значения $\mathrm{pK}_{\mathrm{b}}$ функциональных групп (табл. 3) практически совпали с таковыми для других партий анионита: 2.03; 4.30 и 7.87, но уменьшилось их количество, как и величина полной обменной емкости. Установлено, что в процессе отмывки анионита от примесей теряется около 10\% наиболее диссоциированных функциональных групп с $\mathrm{pK}_{\mathrm{b}}=2.03$; почти $36.5 \%$ - от количества групп со средней степенью ионизации и 44.4 $\%$ - от групп наименее ионизированных. То есть, при кондиционировании значительно уменьшается содержание менее ионизированных групп при общей потере около 20-ти процентов полной обменной емкости.

Влияния годовой эксплуатации анионита на величину константы диссоциации функциональных групп не обнаружено. При этом установлено увеличение ПОЕ работавшего образца почти на $20 \%$ после его радикальной обработки солещелочным раствором. Это очевидный результат «разблокирования» ионогенных групп анионита, «заблокированных» большими органическими молекулами гуминовых и фульвокислот. При этом количество сильноионизированных групп, ставших доступных ионному обмену, возросло на $15 \%$.

\section{Заключение}

Установлено, что высокоосновный анионит АВ-17-8 не является монофункциональным. Кривые водного и неводного потенциометрического титрования указывают на присутствие трех типов функциональных групп. Количество низкоосновных групп может достигать 34\% от полной обменной емкости. Специалисты, синтезировавшие анионит АВ-17-8 [21], считали возможным образование кроме четвертичного аммониевого основания также третичных аминогрупп на стадии аминирования хлорметилированного сополимера стирола и дивинилбензола и других аминогрупп, что и подтверждают представленные результаты.

Константы ионизации функциональных групп разных партий анионита и образцов, подвергшихся разным воздействиям в процессе подготовки к работе и после использовании в лабораторных опытах, практически не изменяются. Установлено, что снижение полной обменной емкости анионита может происходить за счет утраты как высокоосновных, так и низкоосновных ионогенных групп. 


\section{Список литературы}

1. Гребенюк В.Д., Мазо А.А. Обессоливание воды ионитами. М. Химия. 1980. $256 \mathrm{c}$.

2. Мамченко А.В., Вайнман А.Б., Пилипенко И.В. // Химия и технология воды. 1997. Т. 19. № 5. С. 488-493.

3. Зяблов А.Н., Байдичева О.В., Калач А.В., Селеменев В.Ф. // Журн. физ. химии. 2008. Т. 82. № 2. C. 384-386.

4. Зяблов А.Н., Елисеева Т.В., Селеменев В.Ф. // Журн. физ. химии. 2003. Т. 77. № 12. C. $2175-2178$.

5. Гельферих Ф. Иониты. М. Изд-во иностранной литературы. 1962. 490 с.

6. Аширов А. Ионообменная очистка сточных вод, растворов и газов. Ленинград. Химия. 1983. 295 с.

7. Семушин А.М., Яковлев В.А., Иванова Е.В. Инфракрасные спектры поглощения ионообменных материалов / Справочное пособие. Ленинград. Химия. 1980. 95 с.

8. Салдадзе К.М. // Хроматография. Ее теория и применение. М. Изд-во АН СССР. 1960. C. 27-32.

9. Муромцева Г.В., Ольшанова К.М., Салдадзе К.М., Копылова В.Д. Исследование свойств ионообменных материалов. М. Наука. 1964. С.108-114.

10. Салдадзе К.М., Ольшанова К.М., Копылова В.Д. // Ионообменные сорбенты в промылиленности. М. Изд-во АН СССР. 1963. С. 66-70.

11. Мягкой О.Н., Суслина Т.Г., Щедрина В.Б. // Синтез и свойства ионообменных материалов. М. Наука. 1968. С. 227-235.

12. Казанцев Е.И., Пахолков В.С., Кокошко 3.Ю., Чупахин О.Н. Ионообменные материа-

\section{References}

1. Grebenyuk V.D., Mazo A.A. Obessolivanie vody ionitami. M., Himiya, 1980, 256 p.

2. Mamchenko A.V., Vajnman A.B., Pilipenko I.V., Himiya i tekhnologiya vody, 1997, Vol. 19, No 5, pp. 488-493.

3. Zyablov A.N., Bajdicheva O.V., Kalach A.V., Selemenev V.F., Zhurn. fiz. Himii, 2008, Vol. 82, No 2, pp. 384-386.

4. Zyablov A.N., Eliseeva T.V., Selemenev V.F., Zhurn. fiz. himii., 2003, Vol. 77, No 12, pp. 2175. лы и их синтез. Свердловск. Изд-во УПИ. 1968. $149 \mathrm{c}$.

13. Gregor H.R., Hamilton M.J., Becher J. Studies. // J. Phys. Chem. 1955. Vol. 59. No 9. pp. 874-881.

14. Katchalsky A., Spitnik P. // J. Polimer Sci. 1947. Vol. 2. No 4. pp. 432-446.

15. Полянский Н.Г., Горбунов Г.В., Полянская Н.Л. Методы исследования ионитов. Москва, Химия, 1976, 206 с.

16. Рыжов Е.М. // Журн. физической химии. 1979. T. 13. № 9. C. 2323-2325.

17. Kunin R., Fisher S. // J. Phys. Chem. 1962. Vol. 66. No 11. pp. 2275-2277.

18. Салдадзе К.М., Копылова В.Д. Комплексообразующие иониты (комплекситы). М. Химия. $1980.336 \mathrm{c.}$

19. Савицкая Е.М. // Ионообменные сорбенты в промышленности. М. Изд-во АН CCCP. 1963. C. 11-20.

20. Киселев Е.Д., Чмутов К.В., Пашков А.Б. // Исследование свойств ионообменных материалов. М. Наука. 1964. С. 163-172.

21. Пашков А.Б., Иткина М.И., Симанчук С.М. // Хроматография и ее применение. М. Изд-во Академии наук СССР. 1960. С. 56 71.

22. Практикум по ионному обмену. Селеменев В.Ф., Славинская Г.В., Хохлов В.Ю., Чикин Г.А. Учебное пособие. Воронеж. Издво Воронеж. гос. ун-та. 1999. 173 с.

23. Практическое руководство по физикохимическим методам анализа / Под ред. Алимарина И.П., Иванова В.М. М. МГУ. 1987. 205 c.

24. Крешков А.П., Быкова Л.Н., Казарян Н.А. Кислотно-основное титрование в неводных средах / Под общей ред. А.П. Крешкова. М. Химия.1967. С. 79-84.

5. Gel'ferih F. Ionity, M., Izd-vo inostrannoj literatury, 1962, $490 \mathrm{p}$.

6. Ashirov A. Ionoobmennaya ochistka stochnyh vod, rastvorov i gazov. Leningrad, Himiya, 1983, $295 \mathrm{p}$.

7. Semushin A.M., Yakovlev V.A., Ivanova E.V. Infrakrasnye spektry pogloshcheniy aionoobmennyh materialov / Spravochnoe posobie. Leningrad, Himiya, 1981, 95 p.

8. Saldadze K.M. // KHromatografiya $i$ ee primenenie. M., Izd-vo Akademii nauk SSSR, 1960, pp. 27-32. 
9. Muromceva G.V., Ol'shanova K.M., Saldadze K.M., V.D. Kopylova, Issledovanie svojstv ionoobmennyh materialov. M., Nauka, 1964, pp. 108-114.

10. Saldadze K.M., Ol'shanova K.M., Kopylova V.D.,/ Ionoobmennye sorbenty $v$ promyshlennosti, M., Izd-vo AN SSSR, 1963, pp. 66-70.

11. Myagkoj O.N., Suslina T.G., Shchedrina V.B., Sintez $i$ svojstva ionoobmennyh materialov, M., Nauka, 1968, pp. 227-235.

12. Kazancev E.I., Paholkov V.S., Kokoshko Z.Yu., Chupahin O.N., Ionoobmennye materialy i ihsintez. Sverdlovsk, Izd-vo UPI, 1968, 149 sp.

13. Gregor H.R., Hamilton M.J., J. Phys. Chem., 1955, Vol. 59, No 9, pp. 874-881.

14. Katchalsky A., Spitnik P., J. Polimer Sci., 1947, Vol. 2, No 4, pp. 432-446.

15. Polyanskij N.G., Gorbunov G.V., Polyanskaya N.L., Metody issledovaniy aionitov, M., KHimiya, 1976, 206 p.

16. Ryzhov E.M., Zhurn. Fiz. Himii, 1979, T. 13, No 9, pp. 2323-2325.

17. Kunin R., Fisher S., J. Phys. Chem., 1962, Vol. 66, No 11, pp. 2275-2277.

Славинская Галина Владимировна - д.х.н., профессор, Воронежский государственный технический университет, профессор. Россия, Воронеж

Куренкова Ольга Валерьевна - к.Х.н., учитель химии. Кадетский корпус (инженерная школа) Военного учебно-научного центра Военно-воздушных сил «Военно-воздушная академия имени профессора Н.Г. Жуковского и Ю.А. Гагарина», Воронеж
18. Saldadze K.M., Kopylova V.D. Kompleksoobrazuyushchie ionity (kompleksity), M., KHimiya, 1980, 336 p.

19. Savickaya E.M., Ionoobmennye sorbenty $v$ promyshlennosti, M., Izd-vo AN SSSR, 1963, pp. 11-20.

20. Kiselev E.D., Chmutov K.V., Pashkov A.B., Issledovanie svojstv ionoobmennyh materialov. M., Nauka, 1964, pp. 163-172.

21. Pashkov A.B., Itkina M.I., Simanchuk S.M., Hromatografiya i ee primenenie, M., Izdvo Akademii nauk SSSR, 1960, pp. 56 -71.

22. Praktikum po ionnomu obmenu. Selemenev V.F., Slavinskaya G.V., KHohlov V.Yu., Chikin G.A. Uchebnoe posobie. Voronezh, Izdvo Voronezh. gos. un-ta, 1999, 173 p.

23. Prakticheskoe rukovodstvo po fizikohimicheskim metodam analiza / Pod red. akademika Alimarina I.P., d.h.n. Ivanova V.M. M., MGU, 1987, $205 \mathrm{p}$.

24. Kreshkov A.P., Bykova L.N., Kazaryan N.A. Kislotno-osnovnoe titrovanie $v$ nevodnyh sredah / Pod obshchej red. A.P. Kreshkova, M., Himiya,1967, pp. 79-84.

Slavinskaya Galina V. - Prof., Voronezh State Technical University, Professor.Russia, Voronezh, e-mail: $\underline{\text { slavgv@ mail.ru }}$

Kurenkova Olga V. - PhD in Chemistry, Teacher of Chemistry. Cadet Corps (engineering school) Military educational and scientific center of the air force "Air Force Academy named after Prof. N.g. Zhukousky and Yuri Gagarin» Russia, Voronezh, e-mail: kovov84@mail.ru 